\title{
Lo que se verá a mi vera de Vera. Probable etimología vera del apelativo y topónimos homónimos
}

\author{
Jairo Javier García Sánchez \\ Universidad de Alcalá \\ jairo.garcia@uah.es
}

\begin{abstract}
Resumen: Se muestra en este trabajo cómo una vez más la homonimia y la paronimia han podido ocultar y soterrar la vera (= verdadera) génesis del sustantivo común vera, así como la de algunos topónimos que parecen contener esa misma voz. Ha sido a partir del más conocido de ellos, el almeriense Vera, de origen prerromano, sobre el que se han construido buena parte de las argumentaciones etimológicas de los demás topónimos, y también del apelativo en cuestión. Sin embargo, las explicaciones de esos nombres de lugar, entre los que también estarían los Beira gallego-portugueses, y de los sustantivos correspondientes, pueden ser diferentes de las que ha hecho suponer el nombre de la población almeriense.
\end{abstract}

Palabras clave: toponimia; etimología; homonimia; vera; beira.

\begin{abstract}
This paper shows how once again homonymy and paronymy might have hidden the true origin of the common noun vera, as well as that of some place names that appear to contain the same word. From the best known of them, Vera in Almeria, of pre-Roman origin, have been based many of the etymological arguments on the other toponyms, and on the noun vera itself. However, the explanations of those place names, among which the Galician and Portuguese Beira would also appear, and of the corresponding nouns, may be different from those which are thought to have originated from the name of the Andalusian village.
\end{abstract}

Keywords: toponymy; etymology; homonymy; vera; beira. 



\section{El sustantivo vera y su discutido origen}

El sustantivo vera posee fundamentalmente el significado de 'orilla', tal como muestra el DRAE, s.v., que también recoge el de 'faja pintada en el interior de una pared, friso' como propio de Salamanca y Zamora ${ }^{1}$. Se entiende bien cómo ese valor fundamental ('orilla') ha creado el de 'al lado próximo' de la locución a la vera 'a la orilla', el cual se advierte en su primera mención en el juego de palabras del título.

Nada que ver tendría, en principio, el fitónimo vera 'árbol americano, de la familia de las Cigofiláceas, semejante al guayaco, con madera muy dura y pesada y de color rojizo oscuro'², que habría de ser palabra distinta.

Luego ya el adjetivo vera 'verdadera' es el femenino de vero $(<$ lat. VERUS, -A, -UM), que ha dejado de usarse por la pujanza del adjetivo verdadero, $-a$, derivado del sustantivo verdad ( $<$ lat. VERITAS, VERITATEM), con el que se asocia más fácilmente, aunque se mantiene muy vivo en la locución adverbial de veras 'con verdad', 'con formalidad, eficacia o empeño's.

Si buscamos el origen del sustantivo, comprobaremos que vera se tiene por palabra de origen prerromano incorporada pronto al latín. Así, el DRAE, s.v., ofrece como etimología, desde su 19. a ed. de 1970, el celtolat. VIRǏA 'anillo, círculo', tras haber corregido la que se daba hasta la edición anterior de 1956, que suponía en ella el lat. ORA 'orilla' - de donde se diría uera, como de ossum, hueso. Ciertamente esta última etimología se antojaba ridícula por tratarse de una ō larga, aparte de no poder explicar el cognado gallego-portugués beira, de bastante

\footnotetext{
* Este trabajo se inserta en el marco de los proyectos de investigación Semántica latino-románica: unidades de significado procedimental. Diferencias conservadoras e innovadoras del latín al español y afinidades con otras lenguas (Ref. FFI2012-34826) y Frontera hispano-portuguesa: documentación lingüística y bibliográfica (Ref. FFI2014-52156-R).

${ }^{1}$ El DCECH, s.v., muestra, además, varios usos geolectales del sur y oeste peninsular: ast. vera 'orilla', bera 'trozo de tierra que se señala para trabajar en un día', leon. vera 'hueco que queda entre el muro y el tejado', bereña 'amelga' en aldeas de Villaviciosa, extrem. vera 'orilla', marag. y berc. vero 'borde, orilla'; por otra parte, and. vera 'lado'; arag. vera 'orilla'.

2 Palabra propia de Venezuela, tal como aparece en el DAmer (s.v. vera).

${ }^{3}$ Adviértase que en latín ueritas (> esp. verdad) era un derivado de uerus, mientras en español verdadero lo es de verdad.
} 
mayor vitalidad. Así lo señala Corominas, quien, aunque desarrolla en el DCECH (s.v. vera) una detallada explicación sobre la palabra y su posible étimo, no llega a una conclusión clara e indica, en sus mismas palabras, que "el origen céltico de beira y vera es verosímil, aunque incierto".

El DCECH descarta a su vez la explicación que consideraba una forma rebeira, a partir de ribeira ( $<$ lat. RIPARIA), por influjo del prefijo re-, desde la que se hubiera producido una aféresis de la sílaba inicial según el modelo de parejas como llano y rellano, hoyo y rehoyo, chão y rechão, canto y recanto ${ }^{4}$. Lo cierto es que, en efecto, son muchos los inconvenientes que plantea esta hipótesis ${ }^{5}$ como para poder valorarla de manera plausible, pero no por ello hay que pensar necesariamente que, en consecuencia, se trate de una palabra prerromana, "una de tantas voces primitivas que se han salvado aferradas al terreno".

El DCECH reconoce que, aunque la mayor vitalidad en tierras gallego-portuguesas favorecería un étimo céltico, su primera aparición y su frecuencia en fuentes andaluzas y extremeñas deja abiertas otras posibilidades. Se apunta, por último, la posible relación con el fr. berge 'ribera' (ant.fr. barge), de etimología igualmente discutida ${ }^{6}$ y que plantea muchos interrogantes. No obstante, precisamente por eso, tampoco se puede afirmar nada en ese sentido que tenga visos de certidumbre?

\footnotetext{
${ }^{4}$ Esta es la etimología que mantiene el DELP (s.v. beira). Por su parte, los diccionarios gallegos y portugueses que recogen etimología generalmente proponen, sin mucha mayor especificación, el origen de beira desde (ri)beira (< lat. RIPARIA). Así, el GDXL (s.v. beira, I 324) para el gallego. De igual manera, el DLPC (s.v. beira, I 506) apunta que beira tal vez sea reducción de ribeira. Y tanto el DHLP (s.v. beira, 425) como su versión electrónica, el DEHLP (s.v. beira), señalan que el origen etimológico es controvertido, pero dan como probable la aféresis desde (ri)beira.

${ }^{5}$ Entre otras razones sería difícil pensar en esa reducción consumada y generalizada tan tempranamente como se documenta beira en gallego-portugués. Las formas documentadas de los topónimos españoles Vera, que ahora se indicarán, tampoco favorecerían esa hipótesis.

${ }^{6}$ El FEW (I, 254a) le supone una base céltica *BARICA, con la que también se relacionaría el galés bargod 'orilla, fimbria'.

${ }^{7}$ Atrás parecen haber quedado otras asociaciones o vinculaciones, como la que mencionaba Menéndez Pidal (1968: 182) al hablar de "extrañas coincidencias entre la terminación -obre y la palabra vera, señalada por Longnon en la toponimia de la Galia como latinización de un antiguo céltico *wober, que se cree significaría 'arroyo"'. A este respecto, tiene interés lo que señala Dauzat (1946: 115-118), ante la inexistencia declarada por parte de celtistas de la huella de tal palabra en celta, y tras la reconstrucción
} 
La etimología celtolatina a partir de VIRǏA, que muestran el DRAE (s.v. vera) y también diccionarios gallegos como el GDS21LG ${ }^{8}$, es la defendida por García de Diego, quien en el DEEH (s.v. vera, 413; virrāre y viria, 1066-1067) recoge vera como voz leonesa relacionada con el cast., murc. vira 'tira de refuerzo y franja del vestido' y el ast. vera 'argolla del astil', procedentes todas de VIRIA, y vinculadas al lat. *vīrāre 'girar, torcer'. Sin embargo, no parece que sea esta la etimología adecuada; menos aún cuando, además del port., gall. beira, se incluye también entre las formas procedentes de VIRIA el cat. vora 'borde, orilla'?

Corominas en el DECLC (s.v. veral) vuelve sobre la explicación dada en el DCECH (s.v. vera) recalcando que son imposibles los intentos etimológicos que se han hecho por deducir vera del lat. RIPA (port. ribeira) y del lat. ŌRA -ni aun forzando el sentido de una combinación ab ora 'desde la costa, o la orilla'-, pero que, en cambio, los topónimos del dominio castellano -alguno documentado desde antiguo-, coincidentes con la Vera de Plasencia, dan una pista razonable: Vera de Almería, documentado Baria / Varia / Bare(i)a en fuentes romanas; Vera cerca del Moncayo, escrito también Bera (1179); y Veruela, no lejos de allí (doc. 1173, 1179, 1245). Finalmente, tras reseñar que la conjetura de un céltico *BARIA, pariente del ant. fr. barge (hoy berge) y del galés bargod 'orilla, fimbria', no quedó establecida en firme ${ }^{10}$, divaga ya cuando cree que las múltiples oscuridades quizás se aclaren mirando hacia alguna otra lengua indoeuropea paracéltica -su recurrente sorotáptico.

realizada por Berthoud de un tipo italo-céltico *vara 'agua' (con topónimos como Vara, Var, Varia...) que podría aclarar ese posible elemento vera de nombre de ríos hallado en bajo latín. Las explicaciones dadas, de acuerdo con el propio Dauzat, no satisfacen plenamente y la cuestión queda sin resolverse.

${ }^{8}$ Se indica que beira proviene del lat. tardío barı̆a o barĕa, procedente a su vez de un prerromano VIRǏA 'anillo, círculo'.

${ }^{9} \mathrm{El}$ cat. vora procede del lat. ORA, con la adición de una $v$-para facilitar la pronunciación de hiatos. Vid. DECLC, s.v.

${ }^{10}$ Tovar (1963: 387-388) explica, en referencia a la ingeniosa etimología de Corominas, que conlleva numerosos problemas, al tratarse de una raíz indoeuropea difícil de establecer, con relación posible con el esp. barga (FEW I, 254a). No obstante, el topónimo Baria ( $>$ Vera) supone un argumento de mucho peso, tanto como que los arqueólogos muestren la presencia de celtas en Almería. 
Lo llamativo del caso es que Corominas se aproxima y llega a tocar y alcanzar la que, según nuestra opinión, es la explicación más probable, al abordar la etimología del cat. veral 'andurrial'"11 -y al explicar algunos topónimos catalanes, como veremos después. Esa explicación es, en realidad, la que adelantan Alcover y Moll en el DCVB (s.v. veral), donde se dice que veral proviene de un lat. vulgar *VARIĀLE, derivado de varŭus, que originariamente indicaría un trozo de tierra diferente de los inmediatos.

Corominas critica la exposición, no tanto por la etimología propuesta -que no da del todo por mala-, sino por la información descontextualizada y parcial que, según el autor, se ofrece en ese diccionario de lo dicho previamente por él acerca de la posible conexión de veral con vereda ${ }^{12}, \mathrm{y}$ también por considerar que la acepción en que Alcover y Moll fundamentan su planteamiento y que toman por etimológica, la primera que se apunta en DCVB (s.v. veral) ("extensió de sembrat que es distingeix dels altres trossos perquè és més alt o més ben espigat $o$ granat"), es solo conocida en la terminología agrícola de algunos pueblos del interior de Mallorca, pero ajena al resto de la isla y a todo el dominio continental.

Para Corominas, la atribución de veral a la familia de VARIUS -y volvemos a reproducir sus palabras- es posible por caminos indirectos y vías ignoradas complicadas que quedan por investigar, pero la sugerida en el DCVB carece de base; otras no se sabe, pero son posibilidades vagas. Según el etimólogo catalán, es mucho más verosímil que una palabra tan auténtica, tan aferrada al terreno, tan del campo de la vieja tierra lacetana, indigete, ceretana y andosina ${ }^{13}$, tenga una raíz, en el fondo, prerromana.

\footnotetext{
${ }^{11}$ Para esta forma, sin embargo, tampoco ofrece una procedencia clara, aunque se decanta más por una prerromana, llegando a elucubrar incluso con una forma céltica BARI-ALE, de acuerdo con lo que sospecha para vera y los topónimos castellanos.

${ }^{12}$ Nos remitimos a DCVB (s.v. veral) y DECLC, (s.v. veral), sin entrar en más detalles sobre la polémica.

${ }^{13}$ Conviene tener en cuenta, no obstante, que en el dominio lingüístico del occidente peninsular tenemos el aparente cognado gallego-portugués beiral, de significados más o menos afines.
} 


\section{Vera en toponimia}

Si vera es un apelativo que hace referencia a una característica o a una parte del terreno, puede considerarse un topónimo primario ${ }^{14}$. De hecho, no resulta extraño hallarlo como topónimo menor que designa la orilla de un río o de otras corrientes de agua.

Vera es, además, como ya se ha mencionado, el nombre de una importante localidad almeriense, en la costa sureste española, y el de alguna otra entidad de población, como Vera de Moncayo o Vera de Bidasoa - Bera es, en este caso, su nombre en vasco, oficial hoy-, así como el de una conocida comarca cacereña, La Vera -la Vera de Plasencia, antes dicha-, que sirve por ello de complemento toponímico a otros varios nombres de población: Aldeanueva de la Vera, Arroyomolinos de la Vera, Collado de la Vera, Jaraíz de la Vera, Jarandilla de la Vera, Losar de la Vera, Madrigal de la Vera, Pasarón de la Vera, Robledillo de la Vera, Talaveruela de la Vera, Valverde de la Vera, Viandar de la Vera y Villanueva de la Vera.

Otros topónimos poblacionales que contienen un componente vera son los asturianos La Vera'l Ríu, La Vera'l Camín y quizá Prevera; o los canarios -más en concreto tinerfeños-La Vera (repetido en La Orotava, Puerto de la Cruz, San Juan de la Rambla y Santa Úrsula), Vera de Erques (Guía de Isora) y La Vera-Carril (La Victoria del Acentejo).

En Galicia se hallan algunos topónimos Vera, pero también Veira, Beira y Beiro, y en esto coincide con los característicos portugueses, entre los que está el corónimo Beira, que daba nombre a una región del centro septentrional de Portugal.

Pasemos a analizar más en detalle cada uno de estos topónimos. Sin duda, el más conocido y más representativo es el del municipio costero almeriense Vera, que no necesita mayor especificación y no lleva, por ello, complemento toponímico. El topónimo ha sido identificado con el Baria de época romana, bien documentado en las fuentes clásicas ${ }^{15}$ -con las variantes Varia, Barea, Bareia o Badia-, que se situaría loca-

\footnotetext{
${ }^{14}$ De acuerdo con Trapero (1995: 34), son topónimos primarios las palabras que tienen como primera (¿y única?) función la de ser topónimos, es decir, la de referirse a accidentes geográficos.

${ }^{15}$ Baream (Cic., Att. 16,4,2); Baria (Plin. 3,19); Bápєıаৎ (Ptol 2,4,9); Bar(r)ia (Ravenn. 305,2 y 343,9); Bariensium (CIL II 5947)...
} 
lizado en la actual pedanía de Villaricos, dentro del término municipal aledaño de Cuevas de Almanzora.

La identificación de Baria con Vera parece segura. Así lo confirman quienes se han ocupado de explicar el topónimo almeriense ${ }^{16}$. Nieto Ballester (1997: 358), por ejemplo, señala que el nombre actual es continuación directa del nombre romano, a su vez adaptación de uno anterior.

Galmés de Fuentes (2000: 99-100) sigue a Corominas y a Tovar (1963: 387-388), y, al abordar el análisis del topónimo Vera, señala que corresponde a la antigua Baria. Añade que el nombre pervive en el topónimo portugués Beira y en el apelativo beira 'orilla', que en español es vera, repetido a su vez en numerosos topónimos, y cuya etimología -tanto la del apelativo como la del topónimo- sería un celta *BARIA, *BAREA 'orilla'. Las confusiones gráficas de $b$ y $v$, ya en el latín hispánico, explicarían la consonante inicial; recuerda que en inscripciones latinas encontramos formas con $V$-, y en el Arcipreste de Hita la forma Bera.

Castaño Fernández (2011: 349-350) apunta que la ubicación antigua justificaría el origen del topónimo actual en Baria, importante colonia fenicia ${ }^{17}$ sobre población ibera, posteriormente ciudad de los bástulos, $\mathrm{y}$ que sería, por tanto, un topónimo de origen prerromano que atestigua el antiguo uso de la voz vera 'orilla', considerada por Corominas -como sobradamente ya se ha visto- de raigambre indoeuropea.

Al margen de las distintas interpretaciones que elucubran sobre el topónimo y su conexión con el apelativo, lo que es indudable -y con esto es con lo que nos debemos quedar por el momento- es que el topónimo Vera se identifica claramente con un Baria, documentado así en época romana ${ }^{18}$, aunque no queda claro de dónde puede proceder

\footnotetext{
${ }^{16}$ El DCECH (s.v. vera) y el DECLC (s.v. veral) ya lo dejaban claro al indicar que la identidad no se funda solo en la semejanza de los nombres, sino en localizaciones inequívocas.

${ }^{17}$ La ciudad de Baria, de fundación fenicia, sería tomada por los romanos hacia el 209 a.C., como se deduce de las noticias conservadas en las fuentes clásicas sobre su asedio y conquista durante la Segunda Guerra Púnica. Vid. López Castro (2005: 6).

${ }^{18}$ De acuerdo con López Castro (2005: 6), la noticia más antigua de las que mencionan la conquista de Baria por Escipión es la de Valerio Máximo (3,7,1: Badiam / Bariam), que compuso su obra hacia el 33 d.C. El topónimo, como hemos visto, ya aparece citado por Cicerón en el siglo anterior.
} 
ese nombre ${ }^{19}$, que se supone anterior. Añadamos a eso, sin que descubramos nada con ello, que la situación de Vera entre los ríos Antas y Almanzora, y especialmente junto a este último ${ }^{20}$, puede ser relevante para la interpretación del topónimo.

Las otras Vera, no documentadas en la Antigüedad, se han explicado generalmente por su situación al lado de un río. Así ha sucedido con la zaragozana Vera de Moncayo, que se encuentra en el valle del Huecha, junto a este río ${ }^{21}$, al noreste del monte de cuyo nombre recibe el complemento $^{22}$. Inmediatamente al sur de Vera de Moncayo se sitúa el Monasterio de Veruela, cuyo nombre, documentado como Berola ${ }^{23}$ en el s. XII, se ha formado claramente como derivado diminutivo de $\operatorname{Vera}^{24}$.

Para la navarra Vera de Bidasoa-Bera es, como ya se ha dicho, su nombre vasco y oficial-, se han dado explicaciones diferentes. Michelena (1997: 69) lo contempla como un posible derivado del vasco behere, bere 'parte inferior', derivado a su vez de be(h)e 'suelo, parte inferior', mientras que Caro Baroja ve más probable que se trate de un nombre personal, aunque el antropónimo no se documente en la $\mathrm{zona}^{25}$.

${ }^{19}$ Es significativo que De Hoz (2010: 431-432) sitúe Baria, junto a Suel y Sexi, entre los nombres de fundaciones fenicias cuya etimología sea insegura o se escape por completo.

${ }^{20}$ López Castro (2005: 5 y 21) reconstruye, además, la topografía de la ciudad fenicia a partir de los trabajos arqueológicos llevados a cabo por él mismo y otros investigadores. De esta manera, indica que inicialmente, en el s. VII a.C., época en la que se funda, el perímetro urbano se situó junto al mar, limitando al suroeste con una torrentera hoy día parcialmente desaparecida. Hacia finales del s. V o comienzos del IV a.C. la ciudad traspasó sus límites suroccidentales extendiéndose al otro lado de la rambla o arroyo que hacía de límite por el frente litoral en dirección a la desembocadura del río Almanzora. Y hacia el cambio de era la ciudad se desplazó hacia el río, lo que pudo suponer la construcción de una nueva Baria, ya en época imperial. Vid. asimismo López Castro et alii (2010).

${ }^{21}$ Gargallo Sanjoaquín (1990: 28) precisa que hoy el pueblo no se encuentra inmediatamente junto al arroyo de la Huecha, pero, en cualquier caso, está muy cerca, en sus proximidades. Así lo pudimos comprobar en nuestra visita a la población.

${ }^{22}$ Corominas, en el DCECH (s.v. vera), no cree casual que hubiera una Vareia en el territorio de los berones, un poco al oeste del Moncayo, si bien esa Vareia es, en realidad, la actual Varea riojana, en Logroño, junto al Ebro y al Iregua, muy cerca de cuando este afluye en aquel.

${ }^{23}$ Vid. DCECH (s.v. vera), donde, junto a Berola (Veruela), se recoge Bera para Vera de Moncayo.

${ }^{24}$ Para este tipo de derivación diminutiva en toponimia, vid. García Sánchez (2008).

${ }^{25}$ Cf. Belasko (1999: s.v. Bera/Vera de Bidasoa, 131-132). 
Sin embargo, ninguna de esas dos hipótesis se apoya en datos fehacientes, por lo que no es en modo alguno descartable que, en realidad, haga referencia a la orilla del río -el Bidasoa en este caso-, como así también creía Corominas.

Albaigès (1998: 130 y 637-638) indica que el nombre de Vera abunda en la geografía española, y aunque sus orígenes etimológicos difieren en cada caso, lo más frecuente es que se refieran a la ubicación de la población en la orilla (vera) de algún río. Sería el caso de Vera de Bidasoa (Bera), a orillas de ese río, y también el de la comarca extremeña, cuyo nombre está plenamente justificado por la hermosura del paisaje, en la vera del río Tiétar. No sucedería lo mismo, de acuerdo con este autor, con la Vera almeriense, asimilada a la antigua Baria o Barea de los bástulos.

Si nos detenemos en el corónimo extremeño Vera, parece que, en efecto, la localización de las tierras en la margen derecha del Tiétar, al pie de la Sierra de Gredos, representa la interpretación más extendida. Así lo expone Castaño Fernández (2004: 181), quien lo refiere al apelativo, para el que a su vez recuerda su origen incierto, probablemente prerromano, y que se remontaría al bajo latín BARIA o BAREA.

Similar explicación se ofrece para los topónimos Vera asturianos y canarios, que en algunos como La Vera'l Ríu parece hacerse evidente. García Arias (2000: 149 y 452) señala que se suele denominar la vera'l ríu, o la oriella, a la margen del río ${ }^{26}$, si bien otras veces puede ser que vera y oriella expresen proximidad, como en La Vera'l Camín. Además, el topónimo Prevera supondría un per vera 'junto a la orilla'. Por su parte, Trapero (1999: s.v. vera, 404-405) supone que Vera, frecuente en Tenerife, tiene en la toponimia canaria el mismo valor que en español general ('orilla'), sin descartar el sentido que le da el DVEG (s.v. vera, 83$)^{27}$, pues también podría ser término dado a los terrenos de cultivo situados en la orilla de los barrancos.

Para los topónimos Vera, Veira y Beira, de Galicia y Portugal, Moralejo Lasso (1977: 122, 294 y 327) remite a la etimología prerromana hasta ahora aducida (*BARIA); mientras la forma Vera sería castellana, Veira sería gallega, y Beira, característicamente portuguesa. Fernandes

\footnotetext{
${ }^{26}$ Riba (< lat. RIPAM) y sus derivados son también frecuentes en la toponimia asturiana.

${ }^{27}$ El DVEG indica que en sentido geográfico se aplica al terreno contenido en forma de vega que se halla entre algunas sierras y ríos, como la Vera de Plasencia, por estar entre las sierras de Béjar y el río Xerte -en realidad el río Tiétar, como acabamos de ver.
} 
(1999: s.v. Beira, 85-86) tampoco discute la etimología prerromana de la palabra beira, como de vera, y esclarece la motivación del importante corónimo portugués, frente a otras hipótesis anteriores, al señalar que proviene del nombre común aplicado a la región marginal del río Coa.

Por otro lado, aunque el resultado pueda ser producto de la paronimia, no deberíamos dejar de considerar topónimos similares, como Beiro o Veiro, o incluso Beiral, para los que, curiosamente, se dan explicaciones muy diferentes ${ }^{28}$.

En el dominio lingüístico del catalán también hay topónimos Vera. Y a partir de algunos de ellos vamos a encontrar claves explicativas de interés, de la mano del propio Corominas, que nos van a mostrar cómo nuestra idea -la que aquí presentamos y vamos a desarrollar-no está en absoluto desencaminada.

Mientras en el OC (s.v. ve-, vi-, VII 448) se indica que los topónimos Vera ahí recogidos -valencianos y del Bajo Penedés- parecen descendientes mozárabes de la misma palabra prerromana *BARIA, que se postula como étimo del portugués beira y del castellano dialectal vera, y se añade algún topónimo más con conservación del diptongo mozárabe (Barranc de La vęira) y con forma masculinizada (Casa del Bero), se explica también el topónimo Beniver, en Benisa (Alicante), con una forma arabizada beneveirä, la cual se toma como procedente del lat. PINNA VARIA 'penya grisa o virolada ${ }^{29}$ (= peña gris o abigarrada, variopinta)'.

Es más, en el OC (s.v. vera, VII 459-460) se toman en consideración varios nombres compuestos con el adjetivo vera "significant 'grisenca' o 'de colors virolats", del lat. VARIUS,-A, como un antiguo Pennavera -al que se compara con Peñalver en Guadalajara-, como La Vallvera, cerca de Valls, y como Valluguera $(<$ Valluvera $<$ Vallevera $<$ Valle varia), mencionado desde el s. X como Balle Varia, Valle Veira o Ballve$r a$. Este topónimo encontraría su motivación en el color variado de las

\footnotetext{
${ }^{28}$ Fernandes (1999: s.v. Beiro, 85), por ejemplo, aparte de mencionar el posible origen germánico de Beiro, se pregunta si no podría estar en él el antropónimo Valerius, como en Veiro, si bien, cuando aborda esta forma (Fernandes, 1999: s.v. Veiro, 573), habla de otras posibilidades, entre las que se situaría el lat. VARIUS, que explicaría fonéticamente el topónimo y las frecuentes flexiones gramaticales de género y número (Veiros, Veiras...).

${ }^{29}$ El propio adjetivo virolat, -ada procede del lat. VARIŎLUS, diminutivo de varius 'de diversos colores'.
} 
viñas, alternando con las peñas y con otros cultivos. Además, se aduce un Coll de berr, que Corominas presume CORTE VARIA "'masia, corral, virolada, grisenca"”.

Es decir, Corominas contempla el étimo VARIUS, -A 'variopinto, de varios colores' para algunos topónimos del tipo $\mathrm{Vera}^{30}$, pero no lo hace para los que ya suponen una referencia a la orilla de un río, a una vera, pues para estos se tendría ese apelativo, que, según él, se remontaría a una base prerromana de cariz indoeuropeo, como parecería indicar a su vez el topónimo almeriense Vera $(<$ Baria).

\section{Nuestra hipótesis etimológica: vera < lat. VARIA}

Hasta aquí hemos ido revisando o repasando lo que se ha dicho sobre el origen del nombre común vera (así como de su cognado gall. y port. beira) y de los topónimos homónimos, que generalmente constituirían -así lo parece- una conversión "onomástica" del primero. El caso del topónimo almeriense Vera, documentado como Baria en época romana, es el más interesante, pues habría razonables dudas de si tiene que ver o no con el apelativo, por lo que no sabemos realmente si uno explica al otro -bajo el supuesto de que el apelativo proceda de la misma forma que el topónimo (Baria) - o en realidad se trata de meros homónimos.

Según la opinión de algunos, como Corominas, Galmés de Fuentes o Castaño Fernández, apelativo y topónimos -incluido el almeriense-, ya sea en español (vera y Vera) o en portugués (beira y Beira), responden al mismo origen y son la misma forma, por lo que para llegar al étimo de ambos se debería partir de la documentada Baria toponímica.

No obstante, eso no tiene por qué ser necesariamente así en todos los casos, pues, como hemos visto también ya, hay algunos topónimos Vera que se interpretan de manera diferente. Por tanto, sería lícito pensar que el topónimo almeriense y el apelativo vera pudieran tener asimismo orígenes distintos.

Pues bien, a la vista de todos estos datos, creemos estar en disposición de reivindicar una hipótesis explicativa del apelativo y de los topó-

\footnotetext{
${ }^{30}$ Un étimo VARIUS, -A lo hemos visto también aducido para otros topónimos de este tipo. González Bachiller (1997: 103), por ejemplo, menciona el topónimo La Baria, en Ezcaray (La Rioja), como procedente de un VARǏA, en el que, frente a los numerosos casos de Vera, la yod no ha quedado atraída por la vocal de la sílaba anterior.
} 
nimos -al menos de algunos de ellos-, la del lat. VARIUS 'variopinto, de colores diversos', que pasamos a exponer y desarrollar a continuación.

Hemos comprobado ya cómo el lat. varius es perfectamente aplicable a la toponimia, pues, por su condición de adjetivo de color, con el significado de 'variopinto, variado, de varios colores, abigarrado' entraría dentro de la frecuente esfera motivadora de los cromotopónimos.

Por otro lado, tenemos el apelativo vera, con el valor de 'ribera, orilla', de etimología incierta, nada clara y muy discutida, que, por el hecho de ser el nombre de una parte del terreno, se puede considerar topónimo primario y de aplicación toponímica en sí mismo.

No se nos hace difícil vincular ambas realidades y suponer que el lat. varius, $-a$ se pudo aplicar como adjetivo a algún sustantivo, como el lat. ripa o su derivado riparia, para denominar el color variopinto de la ribera y acabar dando lugar al cast. vera y al gallego-portugués veira / beira, como topónimos y, al mismo tiempo, apelativos.

Es en la orilla, en la ribera, precisamente por la cercanía del agua, donde con mayor facilidad surge la vegetación multicolor, que es lo que podría haber determinado el uso del adjetivo como característica específica del terreno. De esta manera, la existencia de un posible RIPA(RIA) VARIA, que no habría de ser la única combinación con el adjetivo ${ }^{31}$, se antoja bastante probable como origen de un resultado final vera. Estaríamos, en todo caso, ante palabras con evidente contacto o contigüidad referencial, lo que favorecería, como es natural, la explicación que aquí se apunta ${ }^{32}$.

Ahora bien, ¿cómo se llega a ese resultado vera? De una parte, se podría presumir una elipsis del sustantivo que atribuyera al adjetivo las propiedades del término elidido, como es lo propio de este fenómeno ${ }^{33}$. Quizá convenga recordar aquí que la elipsis del sustantivo es un proce-

\footnotetext{
${ }^{31}$ Ya hemos visto otros ejemplos aportados por Corominas de parejas constituidas por un sustantivo y el adjetivo varia (penna varia, valle varia, corte varia).

${ }^{32}$ Con el agua y la llegada del buen tiempo se produce la floración en la ribera, que se vuelve varia 'colorida, multicolor', lo que constituye una excelente referencia para toda vera.

${ }^{33}$ La elipsis es un fenómeno sintagmático por el que la contigüidad de significantes favorece que se omita uno o más de ellos, de manera que la palabra que permanece adquiere el valor semántico de todo el grupo y representa en el uso a todo ese sintagma originario. Generalmente la especificidad del adjetivo contiguo propicia que se elida el sustantivo, y aquel pase a ser el sustantivo. Para un análisis global de la elipsis, vid. Paredes Duarte (2009).
} 
dimiento denominativo frecuente, análogo a otros que de igual modo se dieron ya en latín y cuyo resultado se aprecia bien en romance ${ }^{34}$.

Desde luego facilita esta hipótesis, así como cualquier otra que tenga que ver con el adjetivo latino VARIA, el hecho de que la evolución fonética desde esta palabra latina al cast. vera y port. beira es absolutamente regular y no ofrece ninguna complicación (VARIA $>v / b$-aira $(>$ beira) $>$ vera).

De otra parte, no sería descabellado considerar una aféresis desde rivera / ribeira ( $<$ lat. RIPARIA), con la ayuda del adjetivo varia y quizás también de ri(v)us ( $>$ esp. río, port. rio), palabra con la que también habría contigüidad referencial. Es decir, la aféresis no se produciría por la supresión de $r i$ - previo paso por $\mathrm{re}_{-}{ }^{35}$, sino directamente de $\mathrm{ri}_{-}{ }^{36}$ por el cruce con varia y ri(v)us.

Hay que pensar que en el momento en que RIPARIA evoluciona a ribaria, con - $b$ - intervocálica que no se distingue de - $v$ - (ribaria, rivaria $>$ port. ribeira, esp. ribera, river $^{37}$ ), la palabra se puede interpretar como un compuesto de dos elementos con los que se establecería una

${ }^{34}$ Así lo hemos hecho notar ya en otro trabajo (García Sánchez, 2015), que explica el origen del esp. brasa, así como del fr. braise e it. brace, a partir de un lat. PARS, PRUNA ABRASA. Cf. también esp. avellana, port. avelã (< lat. ABELLĀNA [NUX]); esp. manza$n a$, port. maçã (< lat. [MALA] MATTIANA); esp. hermano, port. irmão, cat. germà $(<$ lat. [FRATER] GERMANUS); esp. primo, port. primo (< lat. [CONSOBRINUS] PRIMUS); esp. martes $(<$ [DIES] MARTIS); fr. fromage $<$ (lat. [CASEUS] FORMATICUS), etc.

${ }^{35}$ Esta solución, ya mencionada y explicada, no convencía. Aquí, en cambio, y valga la redundancia, no haría falta recurrir a la recurrencia del prefijo re-.

${ }^{36}$ Vid. nota 4.

${ }^{37}$ Resulta llamativo, aunque en realidad es sintomático, que el DRAE (s.v. rivera) otorgue a rivera ('arroyo, pequeño caudal de agua continua que corre por la tierra', 'cauce por donde corre') una etimología a partir del lat. RIVUS 'riachuelo' y no del lat. RIPARIA, que, además del esp. ribera y port. ribeira, ha dado lugar al fr. rivière 'río' y al it. riviera (oc. ribiera). Por otro lado, el cat. riera se interpreta como derivado de riu (< lat. RIVUS), sin necesidad de recurrir a un lat. *RIVARIA (DECLC, s.v. riu, VII 341), aunque el DCVB (s.v. riera, IX 488) le da esa etimología -lat. RĪVARǏA, de rivu. Lo curioso es que este mismo diccionario (DCVB, s.v. rivera, IX 508) considera rivera una grafía incorrecta de ribera, y, asimismo, el DECLC (VII 348) remite rivera a ribera. Las formas medievales rivaria, riveria, rivarius ('custos ripae') y otras que hallamos en el GMIL (VII 197) son claramente procedentes de RIPA y RIPARIA. En este mismo glosario de ámbito galorrománico se observa el importante número de derivados que tiene ripa para expresar distintos conceptos en relación con lo que, en principio, sería la ribera (cf. además AD-RIPARE > esp. arribar, fr. arriver, it. arrivare). Esto nos hace comprender la relevancia de esta palabra y la de su primer valor, la parte exterior del 
fácil asociación: el primero se correspondería con ri(v)us, y el segundo se podría relacionar con varius. La asociación con ri(v)us se observa claramente por el hecho de que en francés RIPARIA pasa a convertirse en rivière 'río' -la presencia o influencia de rivus sin duda está ahíi ${ }^{38}$. Ese cruce pudo facilitar, a su vez, el aislamiento del segundo elemento baria / varia como vera. Es decir, si RIPARIA evoluciona a ribera / rivera (cf. fr. rivière) y se identifica el primer elemento con río $(<$ lat. RI(V)US), se puede aislar un segundo elemento (baria, varia), ayudado, además, por la identificación y cruce con varia, de VARIUS, -A, -UM, del que se llega a varia, vera, beira, etc.

Cualquiera de estas posibilidades, si no un poco todas, pudo propiciar los apelativos vera y beira, así como los topónimos homónimos, incluyendo ahora también los que presentaban cierta variación -morfemática-, como Vero(s), Veiro(s) o Beiro(s), para los que valdría, en todos los casos, un origen desde el lat. VARIUS, -A, UM 'variopinto', 'colorido'.

El topónimo almeriense, sin embargo, no se incluiría entre ellos, ya que sus formas documentadas hacen suponer -en este caso sí- una forma prerromana anterior ${ }^{39}$. La adopción y adaptación del topónimo por los romanos, con una forma muy parecida a la del adjetivo que aquí estamos viendo, provocaron su posterior evolución de manera prácticamente regular hasta la Vera que conocemos, por lo que coincidiría con el apelativo y con los topónimos Vera que pudieran proceder del lat. (RIPARIA) VARIA / (RI)PARIA (VARIA) o del apelativo romance o protorromance ya constituido.

río, contigua al río, que terminaría asumiendo, ayudada por la homoninia / paronimia, el propio valor de 'río'.

${ }^{38}$ Como acabamos de ver, y queda reseñado en la nota anterior, el esp. rivera ha experimentado la misma asociación.

${ }^{39}$ Ciertamente se nos hacía atractiva la idea de que el topónimo Vera, en Almería, procediera asimismo de un lat. VARIA 'de diversos colores', aplicado a RIPA(RIA), pero hoy por hoy, y a la vista de los datos, descartamos esa posibilidad en aras de una confluencia homonímica con el apelativo y los otros topónimos, que, en cambio, sí consideramos de este origen. 


\section{La importancia del lat. varius en la creación de apelativos y del color como factor motivador de topónimos}

Muchos nombres comunes de uso corriente hoy en español y en otras lenguas romances, y de significados diversos, provienen de denominaciones de color que se daban generalmente en latín. Entre ellos quizá destaquen, por su especial interés, algunos zoónimos. Así, por ejemplo, los étimos de cocho $(<$ COCCEUM) y cochino $(<$ COCCINUM) hacen referencia directa al color rojo de la agalla de la cochinilla (coccum $)^{40}$.

No nos vamos a detener en ellos, pues han sido estudiados y analizados en trabajos de otros investigadores, pero, como vemos, no es una osadía buscar el étimo de determinadas palabras romances en adjetivos latinos de color. Y desde luego tampoco lo es buscarlo y encontrarlo en un adjetivo de tantas aplicaciones como VARIUS. En él, por ejemplo, está el origen del esp. guarro ('cerdo'), que designaría en principio el cerdo 'pinto', según se ve en Petronio (45,2: porcus uarius) ${ }^{41}$, y que, de manera similar, como denominación de color ha terminado designando también otras especies, como un tipo de águila pequeña en guarra, guarrilla, guarro ${ }^{42}$.

La productividad del lat. VARIUS como étimo y base de palabras cuyo origen no se percibe hoy no se detiene aquí, si bien, al margen de vera, no toca hablar ahora de ello, por lo que dejaremos este apartado pendiente de continuación.

Por otro lado, una de las causas más importantes que explican las denominaciones toponímicas o, si se prefiere, uno de los factores referenciales básicos en que se fijan los nominadores o "creadores" de topónimos, es la caracterización por el color, la descripción cromática. En efecto, el color es una de las determinaciones preferidas a la hora de establecer el nombre de los lugares, pues en ocasiones se manifiesta como un rasgo muy visible y llamativo del terreno, algo que destaca y permite establecer una referencia de inmediato. Y esto es así casi de manera universal e independientemente de la lengua en la que surjan los topónimos.

\footnotetext{
${ }^{40}$ Cf. García-Hernández (2013a: 51-59).

${ }^{41}$ La palabra guarro no procede de la voz onomatopéyica guarr-, gorr-, imitativa del gruñido del animal, como sigue manteniendo el DRAE, s.V., sino de la aplicación al nombre del animal del adjetivo varius, esto es, del lat. (PORCUS) VARIUS.

${ }^{42}$ Cf. García-Hernández (2013b: 547-548).
} 
No obstante, no todos los colores tienen el mismo peso en toponimia. La cromotoponimia se da, sobre todo, con colores que destacan sobre los demás y que, como es lógico, se puedan encontrar en el paisaje. Así, el blanco, por su fácil asimilación a lo luminoso y brillante, y el rojo, por su rápida visibilidad, son colores frecuentes en la toponimia española en sus distintas variantes léxicas y de expresividad de matices tonales.

Esto, que es válido para la toponimia en general, sirve también por supuesto para la toponimia de poblaciones. Ya vimos en García Sánchez (2007: 259-265) cómo los cromotopónimos son, en efecto, uno de los grupos toponímicos más prolíficos a este respecto. Así, a los numerosos topónimos que contienen el adjetivo latino albus (Cerralbo, Grijalba, Pedralba, Torralba, Villalba...), se unen los más recientes creados con blanco (Castilblanco, Pozoblanco...) u otras palabras (Aguas Cándidas), entre las que también se hallan las de étimo árabe (Albaida). Por su parte, el rojo es, sin duda, uno de los colores más aludidos ${ }^{43}$ en los topónimos mediante sus varias y diversas manifestaciones (Rubio/Royo, Rojo, Bermejo, Colorado, Grana, Tinto, Almagro, Alhambra, etc). El pardo, como color característico de la tierra, y el verde, como indicador de lugares con vegetación, son asimismo bastante comunes.

No ha de extrañar, por tanto, que una profusión de colores variopintos constituya, precisamente por esa circunstancia, un factor decisivo a la hora de identificar un lugar y que pueda surgir una denominación toponímica o geográfica a partir de ella. Eso es lo que creemos que ha sucedido con el adjetivo VARIA 'variopinta, colorida, de diversos colores', seguramente referido a la orilla, a la ribera, que al llegar la época primaveral echa una abundante, diversa y vistosa floración, para llegar a convertirse en vera.

De la presencia del lat. VARIUS en toponimia no queda duda alguna, por otra parte, por lo dicho ya en los apartados precedentes, no ya solo por nosotros, sino por otros autores como el propio Corominas ${ }^{44}$.

En conclusión, la relevancia referencial que supone el color ha favorecido la creación de apelativos, y también -en un proceso similar,

\footnotetext{
${ }^{43}$ El rojo es el color por excelencia, el color arquetipo, el primero de todos los colores. En muchas lenguas la palabra que significa 'rojo' es la misma que hace alusión a lo 'coloreado'. De hecho, en español tenemos colorado ('que tiene color', 'que por naturaleza o arte tiene color más o menos rojo'). Cf. DRAE, s.v.

${ }^{44} \mathrm{Cf}$. supra.
} 
pero diferente a la vez- la creación de topónimos. Esa doble condición parece verse bien representada y sintetizada en el adjetivo VARIUS, que, como aquí se ha defendido, puede estar detrás del sustantivo vera y de los topónimos que responden a la misma forma; y ello pese a que con cierta seguridad el topónimo Vera más conocido -el de la costa almeriense- muestre, sin embargo, un origen distinto.

Mientras Vera en Almería sea posiblemente un topónimo de origen prerromano, quizá fenicio, los otros Vera, así como el mismo nombre común vera (y sus cognados gallegos y portugueses Beira / beira) pueden tener como étimo el lat. VARIA aplicado a ripa o riparia. La explicación, desde un plano formal y evolutivo, es diáfana, pero también lo es, según hemos tratado de señalar, desde un punto de vista semántico y referencial.

\section{Bibliografía}

Albaigès, Josep Maria. 1998. Enciclopedia de los topónimos españoles. Barcelona: Planeta.

Belasko, Mikel. 1999. Diccionario etimológico de los nombres de los pueblos, villas y ciudades de Navarra. Apellidos navarros (2. ${ }^{a}$ ed.). Pamplona: Pamiela.

Castaño Fernández, Antonio M. 2004. Los nombres de Extremadura. Estudios de toponimia extremeña. Mérida: Editora Regional de Extremadura.

Castaño Fernández, Antonio M. 2011. Andalucía y Ceuta-Melilla. En García Arias, X. Ll. (coord.) \& Casanova, Emili (ed.) Toponimia hispánica. Origen y evolución de nuestros topónimos más importantes. Valencia: Denes, 319-352.

DAmer $=$ Real Academia Española. 2010. Diccionario de americanismos, Madrid: Santillana, Real Academia Española, Asociación de Academias de la Lengua Española.

Dauzat, Albert. 1946. La toponymie française. París: Payot.

DCECH = Corominas, J. \& Pascual, J. A. 1980-1991. Diccionario crítico etimológico castellano e hispánico. Madrid: Gredos (6 vol.).

DCVB = Alcover, Antoni Maria \& Moll, Francesc de B. 1993. Diccionari català-valencià-balear. Palma: Moll (10 vol.). http://dcvb.iecat.net.

De Hoz, Javier. 2010. Historia lingüistica de la Península Ibérica en la Antigüedad. I. Preliminares y mundo meridional prerromano. Manuales y Anejos de "Emerita" - L. Madrid: CSIC. 
DECLC $=$ Coromines, Joan. 1980-1995. Diccionari etimologic $i$ complementari de la llengua catalana. Barcelona: Curial Edicions Catalanes/La Caixa (9 vol.).

DEEH = García de Diego, Vicente. 1985. Diccionario etimológico español e hispánico (2. ${ }^{\mathrm{a}}$ ed. aumentada a cargo de Carmen García de Diego). Madrid: Espasa-Calpe.

DEHLP = Dicionário Electrônico Houaiss v3.0 (da Língua Portuguesa) [recurso electrónico]. Fabricante: FL GAMA DESIGN Ltda. 2009.

DELP = Machado, José Pedro. 2003. Dicionário etimológico da língua portuguesa (8. ${ }^{\mathrm{a}}$ ed.). Lisboa: Livros Horizonte.

DHLP $=$ Houaiss, Antônio \& de Salles Villar, Mauro. 2001. Dicionário Houaiss da Língua Portuguesa. Río de Janeiro: Instituto Antônio Houaiss de Lexicografia, Editora Objetiva.

DLPC = Malaca Casteleiro, João (coord.). 2001. Dicionário da Lingua Portuguesa Contemporânea. Lisboa: Academia das Ciências de Lisboa/ Editorial Verbo (2 vol.).

DRAE $=$ Real Academia Española. 2014. Diccionario de la lengua española

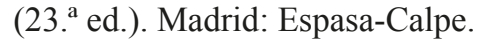

DVEG $=$ Real Academia de la Historia. 1990. Diccionario de Voces Españolas Geográficas (ed. facsímil de la ed. de ca. 1800). Madrid: Aguilar.

Fernandes, Armando De Almeida. 1999. Toponímia Portuguesa (Exame a um Dicionário). Arouca: Associação para a defesa da cultura arouquense.

FEW $=$ Wartburg, Walther von. 1922-2002. Französisches etymologisches Wörterbuch. Eine Darstellung des galloromanischen Sprachschatzes. Bonn/Leipzig/Basilea: Klopp/Teubner/Zbinden.

Galmés de Fuentes, Álvaro. 2000. Los topónimos: sus blasones y trofeos (la toponimia mítica). Madrid: Real Academia de la Historia.

García Sánchez, Jairo Javier. 2007. Atlas toponímico de España. Madrid: Arco/Libros.

García Sánchez, Jairo Javier. 2008. Derivación sufijal propiamente toponímica en los nombres de lugar hispánicos. En Company Company, Concepción \& Moreno de Alba, José G. (ed.) Actas del VII Congreso Internacional de Historia de la Lengua Española II. Madrid: Arco Libros, 1301-1317.

García Sánchez, Jairo Javier. 2015. Brasas: carbones (CGL III, 598, 7). El discutido origen del fr. braise, it. brace y esp. brasa. Revue de Linguistique Romane, en prensa.

García-Hernández, Benjamín. 2013a. Del lat. coccum, cocceus y coccinus al esp. coco, cocho, cochino y cochinilla. Revista de Filología Española 93: 41-70. 
García-Hernández, Benjamín. 2013b. Innovaciones latinas y románicas en el campo léxico de sūs ('cerdo'). En Casanova Herrero, Emili \& Calvo Rigual, Cesáreo (ed.) Actas del XXVI Congreso Internacional de Lingüistica y de Filología Románica IV. Berlín: Walter de Gruyter, 543550.

Gargallo Sanjoaquín, Manuel. 1990. Toponimia turiasonense (I). Archivo de Filología Aragonesa 44-45: 9-36.

GDS21LG = Pena, Xosé Antonio (dir.). 2005. Gran dicionario Século 21 da lingua galega. Vigo: Galaxia/Do Cumio.

GDXL = Carballeira Anllo, Xosé María (coord.). 2009. Gran Dicionario Xerais da Lingua. Obra completa. Vigo: Xerais (2 vol.).

GMIL = Du Cange. 1954. Glossarium mediae et infimae latinitatis (reimpr. de la ed. de Léopold Favre de 1883-1887). Graz: Akademische Druck- u. Verlagsanstalt (10 vol.).

González Bachiller, Fabián. 1997. Aspectos fonéticos de la toponimia riojana actual. Logroño: Universidad de La Rioja.

López Castro, José Luis. 2005. Astarté en Baria. Templo y producción entre los fenicios occidentales. Archivo Español de Arqueología 78: 5-21.

López Castro, José Luis; Martínez Hahnmüller, Víctor \& Pardo Barrionuevo, Carmen Ana. 2010. La ciudad de Baria y su territorio. Mainake 32: 109-132.

Menéndez Pidal, Ramón. 1968. Toponimia prerrománica hispana. Madrid: Gredos.

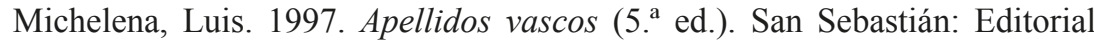
Txertoa.

Moralejo Lasso, Abelardo. 1977. Toponimia gallega y leonesa. Santiago de Compostela: Pico Sacro.

Nieto Ballester, Emilio. 1997. Breve diccionario de topónimos españoles. Madrid: Alianza Editorial.

NTLLE $=$ Real Academia Española. 2001. Nuevo tesoro lexicográfico de la lengua española. Madrid: Espasa-Calpe. http://buscon.rae.es/ntlle/SrvltGUILoginNtlle.

OC $=$ Corominas, Joan. 1989-1997. Onomasticon Cataloniae. Els noms de lloc i noms de persona de totes les terres de llengua catalana. Barcelona: Curial Edicions Catalanes/La Caixa (8 vol.).

Paredes Duarte, M. Jesús. 2009. Perspectivas semánticas de la elipsis. Madrid: Arco/Libros.

Tovar, Antonio. 1963. Les traces linguistiques celtiques dans la Péninsule Hispanique. Celticum 6: 381-403. 
Trapero, Maximiano. 1995. Para una teoría lingüistica de la toponimia (estudios de toponimia canaria). Las Palmas de Gran Canaria: Universidad de Las Palmas de Gran Canaria.

Trapero, Maximiano. 1999. Diccionario de toponimia canaria. Léxico de referencia oronímica. Las Palmas de Gran Canaria: Gobierno de Canarias, Consejería de Educación, Cultura y Deportes, Fundación de Enseñanza Superior a Distancia de Las Palmas y Centro Asociado de la UNED de Las Palmas. 
